\title{
O regresso ao lar em tempos de pandemia: formas de trabalho e de educação em casa
}

\author{
Homecoming in times of pandemic: forms of work and education at home \\ Retour à la maison en temps de pandémie: formes de travail et d'éducation à la maison
}

\author{
Sthéfany Araújo Melo ${ }^{1}$ \\ Instituto Federal do Triângulo Mineiro \\ Robson Luiz de França ${ }^{2}$ \\ Universidade Federal de Uberlândia
}

\begin{abstract}
Resumo: Em virtude da pandemia iniciada em 2019 pelo Coronavírus (Covid-19), o mundo se viu impelido a permanecer em isolamento social por um longo período, a fim de evitar aglomerações e consequente disseminação do vírus. Nessa época, foram necessárias alternativas que permitissem à sociedade a continuidade de suas atividades no âmbito residencial; para isso, o trabalho e a educação foram liberados a serem realizados remotamente. Este artigo fez parte de pesquisa para tese de Doutorado em Educação, pela Universidade Federal de Uberlândia (UFU) e objetivou reunir as concepções de trabalho em casa, a partir de preceitos de Prost e Vincent (2009), e de educação em casa, permeando as ideias de Ensino Remoto Emergencial (ERE), Educação a Distância (EAD) e Educação Domiciliar. Apoiados em uma pesquisa bibliográfica e documental, o trabalho almejou problematizar a nova perspectiva do lar, enquanto ambiente de trabalho e de estudo, que, em tempos passados, foi bastante comum, assim como novamente se tornou em razão da Covid-19, caracterizando-se como um efeito bumerangue.
\end{abstract}

Palavras-chave: Trabalho. Educação. Casa. Pandemia.

\begin{abstract}
Due to the pandemic started in 2019 by the Coronavirus (Covid-19), the world was forced to remain in social isolation for a long period, in order to avoid agglomerations and consequent spread of the virus. At that time, alternatives were needed that allowed society to continue its activities in the residential sphere; for this, work and education were allowed to be carried out remotely. This article was part of a research for a Doctoral thesis in Education at the Federal University of Uberlândia (UFU) and aimed to bring together the concepts of work at home, based on the precepts of Prost and Vincent (2009), and of education at home, permeating the ideas of Emergency Remote Learning (ERE), Distance Education (EAD) and Homeschooling. Supported by a bibliographical and documental research, the work aimed to problematize the new perspective of the home, as a work and study environment, which, in times past, was quite common, as well as once again became due to Covid-19, characterizing it if like a boomerang effect.
\end{abstract}

Keywords: Work. Education. Home. Pandemic.

\footnotetext{
${ }^{1}$ Mestrado em Educação Profissional e Tecnológica pelo Instituto Federal de Educação, Ciência e Tecnologia do Triângulo Mineiro (IFTM). Atua no Instituto Federal do Triângulo Mineiro - Campus Uberlândia, UberlândiaMG, Brasil. E-mail: sthefany@iftm.edu.br. Lattes: http://lattes.cnpq.br/9322228644060538. ORCID: https://orcid.org/0000-0002-8568-9550.

2 Doutorado em Educação Escolar pela Universidade Estadual Paulista Júlio de Mesquita Filho. Atua na Universidade Federal de Uberlândia (UFU), Uberlândia-MG, Brasil. E-mail: rlfranca@ufu.br. Lattes: http://lattes.cnpq.br/649491951 1957208. ORCID: https://orcid.org/o0o0-0002-6932-3890.
} 
Resumé: En raison de la pandémie déclenchée en 2019 par le Coronavirus (Covid-19), le monde a été contraint de rester en isolement social pendant une longue période, afin d'éviter les agglomérations et la propagation conséquente du virus. A cette époque, il fallait des alternatives qui permettent à la société de poursuivre ses activités dans la sphère résidentielle ; pour cela, le travail et l'éducation ont été libérés pour être effectués à distance. Cet article s'inscrivait dans le cadre d'une recherche pour une thèse de doctorat en éducation à l'Université fédérale d'Uberlândia (UFU) et visait à rapprocher les concepts de travail à domicile, basés sur les préceptes de Prost et Vincent (2009), et d'éducation à à la maison, imprégnant les idées d'apprentissage à distance d'urgence (ERE), d'enseignement à distance (EAD) et d'enseignement à domicile. Soutenu par une recherche bibliographique et documentaire, le travail visait à problématiser la nouvelle perspective de la maison, en tant qu'environnement de travail et d'étude, qui, dans le passé, était assez courant, ainsi que redevenu dû à Covid-19, caractérisant c'est comme un effet boomerang.

Mots-clés: Travail. Éducation. Loger. Pandémie.

Recebido em: 09 de julho de 2021

Aceito em: 17 de agosto de 2021

\section{Introdução}

Um vírus identificado em uma província da China, em dezembro do ano de 2019, trouxe à humanidade um cenário assustador. Afetando todos os continentes do globo terrestre, o Coronavírus (SARS-CoV-2), causador da doença Covid-19 (Corona Virus Disease) ocasionou mais uma pandemia, assim como ocorreu com os casos de peste bubônica, varíola, cólera e gripe suína $\left(\mathrm{H}_{1} \mathrm{~N}_{1}\right)$. As infecções causadas pela Covid-19, facilmente confundidas com os sintomas gripais, apresentavam alta capacidade de transmissão por meio de gotículas expelidas pelo nariz ou pela boca de pessoas acometidas pela doença.

Nesse panorama, frente à necessidade iminente de se conter a propagação do vírus em todo o mundo, os impactos sociais foram inevitáveis. No contexto econômico, todos os segmentos do comércio de produtos e de prestação de serviços foram afetados. Na tentativa de se evitar a concentração de pessoas em um mesmo local, muitos trabalhadores foram autorizados pelas chefias a executarem a sua jornada de trabalho em casa, implementando o não tão conhecido à época home office. Para os trabalhadores da educação não foi diferente, com as aulas suspensas e seus colaboradores em casa, as instituições de ensino, sob a justificativa de amenizar os impactos causados pela Covid-19 aos estudantes, estruturaram o home office na educação, também conhecido como ensino remoto.

Assim, de maneira a se adaptarem a uma nova realidade, as formas de trabalho e de educação foram atualizadas para o seu desenvolvimento no isolamento do lar. Processos tão 
pouco imaginados serem praticados em casa, a partir de 2020 foram abruptamente colocados em prática. Para isso, este artigo objetivou organizar as concepções de trabalho em casa a partir dos postulados de Prost e Vicent (2009), de modo a compreendermos as representações históricas de trabalho no âmbito residencial, percorrendo conceitos como o de trabalho em domicílio, trabalho autônomo e trabalho doméstico. Quanto às concepções de educação em casa, atravessamos preceitos sobre Ensino Remoto Emergencial (ERE), Educação a Distância (EAD) e educação domiciliar, conhecida internacionalmente como homeschooling.

Dessa forma, de modo a problematizar a nova perspectiva do lar, enquanto ambiente de trabalho e de estudo, o contexto econômico e educacional ocasionado pela Covid-19 ofereceu a oportunidade de indagarmos: É possível realizar as atividades laborativas e pedagógicas no âmbito residencial? É possível atingir todos os objetivos realizando tais atividades em casa? É possível cumprir a carga horária de trabalho ou de estudos com pontualidade? Tais atividades podem ser prejudicadas pelo emaranhamento com as atividades domésticas? Ou a carga horária se excede pela confusão entre tempo de trabalho/estudo e tempo de descanso? Manter trabalhadores e alunos em casa é uma medida provisória pela conjuntura sanitária imposta pela Covid-19 ou é um processo de aceitação para o futuro?

Isto posto, no tocante ao cenário da pandemia Covid-19, o que antes era visto como um fenômeno marginal e residual a poucos indivíduos, tornou-se comum e institucionalizado, seja em forma de trabalho ou de ensino remoto. Diante disso, colocamonos a pensar na hipótese de estarmos, de fato, diante de um efeito bumerangue. De um lado, o trabalho e a educação noutrora oferecidos em casa devido à falta de recursos pela família, seguida pela natural evolução social, que retraiu as atividades laborativas e educacionais do âmbito residencial. A evolução do trabalho assalariado levou os trabalhadores às indústrias, assim como a educação, provida pelo Estado por meio das escolas, tornou-se direito social de todos os brasileiros. E, desde o ano de 2020, retornamos aos tempos ancestrais pelo trabalho e estudo em casa, porém facilitados pelas Tecnologias Digitais da Informação e da Comunicação (TDIC), e sob os olhos atentos do mundo capitalista que saberá fazer proveito da ocasião.

\section{O trabalho em casa}

Neste tópico resgatamos concepções de trabalho pouco lembradas, quais sejam aqueles realizados em casa, dentro do ambiente familiar, aquele realizado em outros ambientes familiares, como os empregados domésticos, as diaristas, as babás ou os cuidadores de idosos, e o próprio trabalho doméstico, aqui entendido como as atividades caseiras para a manutenção do lar, como a limpeza da casa e as tarefas de lavar e passar roupas (Figura 1). Para isso, entendemos 
o trabalho como a atividade humana em que os indivíduos têm como objetivo, por meio de suas próprias habilidades e capacidades, produzir formas de manutenção da sua subsistência.

Figura 1 - Formas de trabalho em casa.

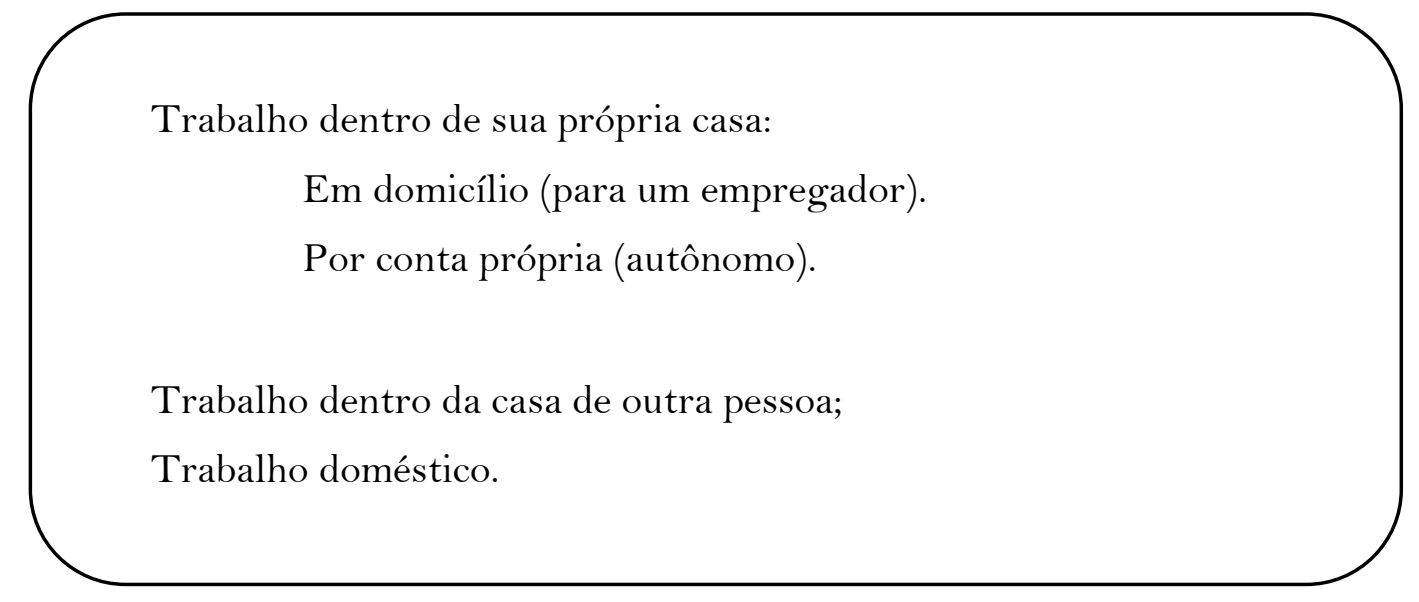

Fonte: Os autores (2021).

Primeiramente, o trabalho realizado em casa contempla duas situações: trabalhar em sua casa para outra pessoa - (a) trabalhadores em domicílio - ou trabalhar em sua casa para si mesmo, (b) por conta própria. Destacamos que o termo "trabalho em domicílio" se vincula sempre ao conceito de prestar serviços a outra pessoa, portanto existirá sempre a figura de um empregador. Nesse primeiro caso (a), como exemplo dos trabalhadores em domicílio em tempos passados temos os tecelães, que se submeteram a angustiantes condições de vida e de trabalho:

[...] eles se impõem condições terríveis de vida e de trabalho: levantando às quatro da manhã, o pai e os filhos descem ao porão, para seus teares; a mãe prepara as tramas, e os teares zumbem até as dez da noite - quinze horas de trabalho efetivo, na umidade e amiúde à luz de velas. Fazem um intervalo de manhã para uma xícara de café de chicória com pão, uma sopa ao meio-dia e outra no final da tarde. (PROST; VINCENT, 2009, p. 22)

Em tempos modernos, a Consolidação das Leis do Trabalho (CLT), em seu artigo 83, apresenta como trabalho em domicílio "aquele executado na habitação do empregado ou em oficina de família, por conta de empregador que o remunere”. Em razão de sua natureza peculiar, torna-se embaraçosa a comprovação da jornada de trabalho por meio de registro de ponto, seja ele manual, mecânico ou eletrônico; dessa forma, os trabalhadores em domicílio podem ser remunerados por tarefa executada, por peça produzida ou por tempo dedicado (dia, semana ou mês). Ainda que o trabalhador efetue os serviços em sua própria residência e não esteja sob o controle direto da empresa, o empregador ainda pode controla-lo estabelecendo metas de produção, prazos para conclusão das tarefas ou apresentação do produto acabado, o que caracteriza a subordinação hierárquica típica de uma relação empregatícia. Para isso, 
preceitua o artigo $6^{\circ}$ da CLT ao mencionar que: "Não se distingue entre o trabalho realizado no estabelecimento do empregador, o executado no domicílio do empregado e o realizado a distância, desde que estejam caracterizados os pressupostos da relação de emprego”. Assim, desde que estejam presentes os requisitos de pessoalidade, de continuidade e de subordinação jurídica, econômica e objetiva caracterizados pelo direito trabalhista, não se pode tratar de forma desigual o trabalho em domicílio.

Como exemplo, em dias atuais temos os analistas de mídias sociais, profissionais de marketing que fazem a gestão das contas nas redes sociais de uma empresa, responsáveis pela criação de posts, monitoramento e performance dos canais oficiais da marca e sua interação com o público; tais profissionais contratados pelos tomadores de serviços costumeiramente executam suas atividades em domicílio. Reforçamos, mais uma vez, que o trabalho em domicílio exige a figura de um empregador ou tomador de serviço, entretanto essa relação deve ser não-eventual, ou seja, ocorrer com frequência e habitualidade; desta forma a relação de emprego não se esgota mediante a realização da tarefa/produto, mas perdura no tempo.

Diferentemente, no segundo caso (b), o trabalho realizado em casa para si próprio, ainda que envolva a existência de um tomador de serviço, não há o caráter de frequência e habitualidade, pois os serviços são eventuais. Atualmente, tais trabalhadores independentes são bem mais numerosos que os trabalhadores em domicílio e, antigamente, representavam-se entre os camponeses, os comerciantes e os artesãos. Hodiernamente, tais trabalhadores são conhecidos como autônomos, microempreendedores individuais (MEI), freelancers ou profissionais liberais; como exemplo temos os eletricistas, fotógrafos, costureiras, guias turísticos, jardineiros, apicultores, personal trainers, confeiteiros e etc. Muitos ainda trabalham exclusivamente em casa, como as costureiras e os confeiteiros, outros prestam seus serviços fora de casa, como os guias turísticos e os personal trainers. Pela Lei $n^{\circ} 5.890$, de 8 de junho de 1973, em seu artigo $4^{\circ}$, o trabalhador autônomo é:

"o que exerce habitualmente, e por conta própria, atividade profissional remunerada; o que presta serviços a diversas empresas, agrupado ou não em sindicato, inclusive os estivadores, conferentes e assemelhados; o que presta, sem relação de emprego, serviço de caráter eventual a uma ou mais empresas; o que presta serviço remunerado mediante recibo, em caráter eventual, seja qual for a duração da tarefa” (BRASIL, 1973, Artigo $4^{\circ}$ ).

O trabalho autônomo, por sua natureza privada, possibilita maior liberdade para o trabalhador, que pode determinar o seu tempo de dedicação ao serviço e não se subordina às normas e metas da empresa. No entanto, em ambos os casos, para aqueles que trabalham em domicílio e para aqueles que trabalham em casa de forma autônoma, a vida e o trabalho se confundem, pois a indiferenciação entre o espaço de trabalho e o 
espaço residencial para descanso acarretam, por consequência, a indiferenciação do tempo dispendido para cada um deles. "De certo modo, a pessoa, quando trabalha em casa, já não tem sua própria casa” (PROST; VINCENT, 2009, p. 24).

Quando se trabalha no espaço residencial, torna-se comum que estranhos, e até mesmo o próprio empregador nos casos de trabalho em domicílio, tenham abertura para procurar o trabalhador em sua residência e, por diversas vezes, fora do horário de expediente, o que gera o emaranhamento entre a vida privada e o trabalho produtivo. Essa mistura já não acontece no trabalho assalariado executado no âmbito da empresa, quando a distinção entre tempo produtivo e tempo de descanso é bem mais delineada, em razão de a venda da força de trabalho se dar exatamente pelo tempo vendido ao empregador.

Historicamente, desde o período da Segunda Guerra Mundial (1939 - 1945), pelo esforço da modernização e pela natural evolução social, o trabalho em domicílio e os trabalhadores autônomos com suas empresas familiares, onde a família inteira era mobilizada a participar da produção, sofreram retração. Após a grande recessão econômica que atingiu o sistema capitalista no início de 1929 e que ocasionou, no Brasil, o Decreto $\mathrm{n}^{\circ}$ 19.554, de 31 de dezembro de 1930, suspendendo temporariamente o pagamento de aposentadorias e pensões, surgiu em 1943 a Consolidação das Leis do Trabalho (CLT). Os direitos trabalhistas unificados pelos 922 artigos da CLT e os benefícios sociais criados posteriormente, como o Fundo de Garantia do Tempo de Serviço (FGTS) pela Lei n ${ }^{\circ}$ 5.107, de 13 de setembro de 1966, ocasionaram a redução das empresas familiares e dos trabalhadores em domicílio, que foram seduzidos pelas vantagens trabalhistas asseguradas durante a venda de sua força de trabalho às empresas.

Contudo, ainda que ocorrera a redução das empresas familiares, do trabalho em domicílio e do pequeno comércio e do artesanato tão comuns à época, houve a facilidade em se registrar os próprios membros da família como funcionários. Médicos registraram suas esposas como secretárias contratadas, pais registraram seus filhos como trabalhadores rurais, e a mudança desse estatuto jurídico fortificou a necessidade de se diferenciar o trabalho produtivo da vida privada, a empresa da família.

Quanto à segunda e à terceira forma de trabalho em casa, é inconcebível as abordarmos separadamente. Falarmos do trabalho realizado em ambientes familiares alheios também envolve falarmos do próprio trabalho doméstico enquanto atividades domiciliares para manutenção do lar. Da mesma forma, tratar desses assuntos exige reflexões que permeiam o trabalho feminino, assim como a depreciação de tais modelos em comparação aos trabalhos assalariados, executados fora de casa, em indústrias ou empresas.

Por sua evolução natural, o trabalho emergiu e se vinculou à ideia de trabalho realizado fora de casa, por empregados rurais, criados, cozinheiras e camareiras, mas ainda restrito ao 
ambiente familiar de outrem. Assim, o trabalho realizado sob o domínio privado de outra pessoa, em razão dos próprios limites físicos de sua residência, se relacionava exclusivamente às atividades que poderiam ser realizadas ali, tais como antigamente faziam as mucamas, cocheiros, copeiras, amas de leite e os camaradas rurais, executando as mais diversas tarefas nas residências de seus patrões. Hoje em dia, podemos citar as babás, mordomos, cuidadores de idosos, caseiros, governantas, motoristas e as empregadas domésticas.

O trabalho realizado em ambientes familiares alheios sempre se relaciona às atividades domésticas, como lavar e passar as roupas, varrer, limpar a casa e os móveis, cozinhar as refeições, cuidar das crianças, tratar dos animais, plantas e cultivos vegetais, realizar manutenções em utensílios, dentre outros afazeres. O trabalho realizado na casa dos outros por muito tempo exigiu que o trabalhador morasse na casa do patrão, não apenas emaranhando a sua vida produtiva com a vida privada, mas, podemos dizer, eliminando qualquer privacidade. Embora, atualmente não seja tão comum que o empregado doméstico resida no seu ambiente de trabalho, esse vínculo tão estreito entre trabalhadores domésticos e patrões permanece até os dias atuais, haja vista a peculiaridade e as atribuições da profissão.

No suscitar dessas questões, percebemos que o trabalho em domicílio explicado por Prost e Vincent (2009) tomou o formato conhecido atualmente como home office, teletrabalho ou trabalho remoto, e nunca antes foi tão consentido como tem acontecido desde a pandemia Covid-19. Não obstante, nos dias atuais o trabalho remoto está intimamente relacionado ao uso das tecnologias, por meio de notebooks, celulares ou tablets. A evolução e a acessibilidade das tecnologias permitiram que o trabalho remoto fosse facilitado diante o cenário pandêmico e, desde 2020, voltou-se a favorecer que as atividades produtivas dos trabalhadores fossem executadas em suas próprias residências, ocasionando um efeito bumerangue.

O regresso à origem das representações laborativas no âmbito domiciliar, por meio do trabalho remoto, já se tornou natural e possível no mundo capitalista e, certamente, já têm se tornado possíveis novas formas de alienação/exploração do novo teletrabalho assalariado. No âmbito educacional, de forma análoga, emergiu o ensino remoto, quando os trabalhadores da educação se viram, de repente, atores de em ensino híbrido, impelidos ao uso das tecnologias digitais no processo de ensino e aprendizagem e ao despontar da modalidade de educação domiciliar, que trataremos no próximo tópico.

\section{A educação em casa}

Assim como o trabalho, sabemos que a educação é um dos direitos sociais previstos na Constituição Federal do Brasil, e que deve ser atendido, junto a outras necessidades vitais básicas, por meio do salário mínimo, outro direito social dos trabalhadores, urbanos e rurais. 
A educação visa ao pleno desenvolvimento da pessoa, seu preparo para o exercício da cidadania e sua qualificação para o trabalho; é, portanto, constitucionalmente um direito de todos e dever do Estado e da família, sendo promovida e incentivada com a colaboração da sociedade.

Perante o cenário da pandemia Covid-19, viabilizar o direito constitucional à educação, sem o tradicional encontro presencial entre professor e alunos, transformouse em um enfrentamento técnico e emocional para ambos. O desafio técnico ocorre pela dificuldade de domínio das tecnologias, seja no trato com os aparelhos digitais (notebooks, celulares, tablets, impressoras, scanners, câmeras e etc.) ou no domínio dos softwares, plataformas ou aplicativos que viabilizam o trabalho das máquinas. O desafio emocional, para alunos e professores, envolve as dificuldades de se adaptarem rapidamente a uma nova realidade, a mudança das práticas pedagógicas no processo de ensino-aprendizagem, a escolha de novas ferramentas para a realização das atividades e a ausência de interação, possibilitada pelo contato social e relacionamento entre todos.

Nesse novo formato de educação em casa, a relação entre professor e alunos ganhou um "novo" componente, a família. Ainda que sempre requisitada na participação educativa dos estudantes, nunca antes a família foi tão inserida nesse processo. Na educação básica (préescola, ensino fundamental e ensino médio), a atuação dos pais/responsáveis foi substancial, principalmente para os alunos mais novos, que careciam de acompanhamento integral na mediação tecnológica para assistirem às aulas. Na educação superior (graduação e pósgraduação), mesmo que os alunos já tenham capacidade para atuarem de forma independente com os desafios tecnológicos, a família se fez ainda substancial frente aos desafios emocionais. O apoio familiar pôde auxiliar nas incertezas e angústias dos alunos nesse novo formato de ensino remoto, em sua adaptação a uma nova rotina de estudos e com o amparo motivacional.

Com efeito, o termo "ensino remoto" despontou para expressar esse novo formato de educação em casa. O que foi chamado de home office na esfera do trabalho, na esfera da educação foi chamado de ensino remoto. E, assim como o trabalho remoto, o ensino remoto foi aceito e institucionalizado. Sabemos que o adjetivo "remoto" traduz o conceito de distanciamento geográfico, ou seja, um ensino que seja remoto é aquele que pode ser efetivado a distância, por meio de uma linha de comunicações. Todavia, a efetivação de um ensino remoto já era possível antes mesmo da pandemia Covid-19, porém foi posto em prática massivamente somente nesse momento de emergência, o que justifica o uso do termo Ensino Remoto Emergencial (ERE).

Devido às peculiaridades que o constituem, advindas de sua natureza emergencial e do modo abrupto com que foi posto em prática, o ERE utiliza o mesmo conteúdo e a mesma logística do ensino presencial. Nele, o professor segue o planejamento que aconteceria fisicamente em sala de aula, mas a distância, com o uso das Tecnologias Digitais da Informação 
e da Comunicação (TDIC). O Ensino Remoto Emergencial envolve, portanto, o uso frequente de aulas síncronas, quando a interação entre professor e alunos acontece ao vivo por meio de alguma TDIC, de forma a substituir o que seriam as aulas presenciais. As aulas gravadas ou os materiais produzidos e disponibilizados aos estudantes também são utilizados, como momentos assíncronos do processo ensino-aprendizagem. No entanto, entendemos que o caráter singular do ERE não se apoia na predominância de momentos síncronos ou assíncronos, mas sim na dinâmica de se manter a mesma rotina da sala de aula em um ambiente virtual. Assim, não é a predominância de aulas síncronas que caracteriza o ERE, como podemos observar, a título de exemplo, no regulamento das atividades didático-pedagógicas em tempos de pandemia Covid-19 do Instituto Federal do Triângulo Mineiro (IFTM), por meio da Resolução Ad Referendum n ${ }^{\circ}$ 62, de 21 de maio de 2021. O $\$ 1$, artigo $6^{\circ}$ do referido regulamento exige o mínimo de $20 \%$ da carga horária da disciplina com atividades síncronas, ficando os $80 \%$ restantes a critério do docente.

Assim sendo, no ERE as aulas podem ser em tempo real ou gravadas, o que se aproxima da modalidade de Educação a Distância (EAD), onde também é possível oferecer momentos síncronos ou assíncronos. Entretanto, os cursos oferecidos na modalidade EAD são totalmente planejados para sua oferta a distância, através dos Ambientes Virtuais de Aprendizagem (AVA) da instituição de ensino ofertante.

As plataformas de AVA disponibilizam funcionalidades com foco em atividades assíncronas, pois sua principal característica é a flexibilidade para que o estudante assista às aulas e tenha contato com o conteúdo do curso de acordo com a sua disponibilidade. As atividades em tempo real descaracterizam a EAD, ainda que sejam possíveis. A participação do aluno e o seu desenvolvimento no curso são medidos pela própria plataforma, na realização das avaliações e nos comentários e feedbacks nos fóruns de discussão. Por esse motivo, na EAD a mediação didático-pedagógica exige a figura de um tutor, que acompanha a atuação dos estudantes dentro da plataforma, suas dificuldades, sejam operacionais ou pedagógicas, e monitoram a sua participação, haja vista a ausência de interação ao vivo entre professor e alunos.

Nessa esteira de pensamento, o Ensino Remoto Emergencial trouxe significativa contribuição ao aprofundar as discussões sobre as maneiras de se implementar o processo educativo em casa. Além de relembrar as suas semelhanças com a EAD, trouxe à superfície um modelo de educação já pensado desde antes de 1994, a educação domiciliar, conhecida também como homeschooling. A educação domiciliar é um modelo pedagógico de aprendizagem em que o aluno desenvolve as suas habilidades, sejam cognitivas ou físicas, por intermédio dos pais ou responsáveis, sem a intervenção de uma instituição regular de ensino. No entanto, mesmo que a 
educação seja oferecida pelos pais em casa, nada impede que as crianças sejam inseridas em escolas de idiomas, de esportes, de artes ou que sejam auxiliadas por professores particulares ou tutores.

Como mencionado na abertura deste tópico, a Carta Magna diz ser dever do Estado e da família a educação de seus filhos. Porém, ao pesquisarmos o que prevê a legislação infraconstitucional dentre as diretrizes e bases da educação nacional, por meio da Lei $n^{\circ}$ 9.394 de 20 de dezembro de 1996, não há nenhuma alusão a formas de educação em casa. Tal legislação regulamenta o sistema educacional brasileiro, público e privado, da educação básica ao ensino superior, e em seu artigo $6^{\circ}$ prevê apenas a obrigatoriedade dos pais ou responsáveis efetuarem a matrícula das crianças na educação básica a partir dos quatro anos de idade. Assim, podemos inferir que se torna obrigatória aos pais/responsáveis a matrícula dos filhos na rede regular de ensino, o que, conjuntamente ao artigo 246 do Código Penal, acarreta crime de abandono intelectual deixar, sem justa causa, de prover à instrução primária de filho em idade escolar.

Em 1994, de autoria do deputado João Teixeira (PL-MT), surgiu a primeira proposta legislativa sobre o tema, com o Projeto de Lei (PL) n ${ }^{\circ}$ 4.657. Nela, havia a previsão de criação do ensino domiciliar de primeiro grau, que seria fiscalizado por órgão competente do Ministério da Educação (MEC), e apresentou como justificativa preencher a lacuna criada pelo alto valor das mensalidades escolares na rede privada. Depois de vários outros projetos de lei, o PL n 3.179, de 08/02/2012 é o que atualmente tramita nas casas legislativas. Junto a ele foram apensados outros 6 projetos similares. Todos eles visam igualmente à regulamentação da educação domiciliar e sua adequação ao sistema de ensino brasileiro.

A educação domiciliar ganhou destaque somente a partir de 2019, quando constou como uma das 35 metas prioritárias dos primeiros cem dias do atual governo, presidido por Jair Messias Bolsonaro (2019-2022), conforme exposto pelo ministro da Casa Civil à época, Onyx Lorenzoni. Desde então, discussões, artigos e reportagens têm se espalhado pela sociedade.

Salientamos que não é objetivo deste estudo aprofundar as discussões sobre educação domiciliar, por sua vez, ainda que o assunto envolva outras circunstâncias a serem ponderadas, é patente que o controle do tempo é essencial para se implementar qualquer processo de ensino em casa. Seja por meio da educação domiciliar, da Educação a Distância ou pelo Ensino Remoto Emergencial, a indiferenciação do espaço confunde o que seria tempo dedicado aos estudos e tempo dedicado ao descanso no lar. Para os alunos, o emaranhamento entre casa e escola pode ser um fator de desmotivação e comprometer o êxito da aprendizagem, se não bem organizado. Para os educadores, tal emaranhamento dificulta a conciliação entre ensino e vida pessoal, por vezes ocasionando que o tempo dedicado ao ensino se estenda por muitas horas. $\mathrm{O}$ mesmo acontece para o trabalho em casa, explicitado no tópico anterior, em razão do trabalho remoto, ou home office. 


\section{Considerações finais}

Sem dúvida, o isolamento social possui importância capital como estratégia de contenção biológica para controlar a disseminação do vírus Covid-19. Todavia, sob o prisma do trabalho, conforme Souza et al. (2021), "essa nova geografia imposta pelo trabalho remoto enfraquece os coletivos de trabalhadores que, historicamente se fortaleceram do próprio local de trabalho, como lugar de encontro e de realização da atividade individual e coletiva”. Em outras palavras, a ausência de convívio social e comunitário, possibilitado pelo trabalho presencial, esmaece não apenas a relação empregatícia, entre empregador e empregado, mas também os laços de identidade dentre os próprios trabalhadores.

O distanciamento aflige igualmente a educação, quando professores, sem a tradicional sociabilização nos ambientes educativos, carecem de alternativas diversas para identificar as reações de dúvida, clareza, curiosidade ou tédio normalmente expressas pelos alunos em sala de aula.

A autonomia, apontada como principal vantagem do trabalho e do ensino remoto, mascara pela flexibilidade de horários, se não for devidamente organizada gera sobrecarga de tarefas para todos os sujeitos. Professores, frente aos desafios técnicos exigidos pela mudança das metodologias de suas aulas; pais, também desafiados pela tecnologia utilizada nas aulas dos filhos; professores que também são pais; pais que também trabalham; trabalhadores que reorganizaram toda a sua rotina familiar, e todos em comum sobrevivendo aos desafios emocionais impostos por uma nova realidade em casa.

\section{Referências}

BRASIL. Decreto $n^{\circ} 19.554$, de 31 de dezembro de 1930. Disponível em: https://www2.camara.leg.br/legin/fed/decret/1930-1939/decreto-19554-31dezembro-1930-5 14609-publicacaooriginal-1pe.html\#: :text=DECRETA\%3A,referem\%200\%20decreto\%2olegislativo\%20n. Acesso em: 03 abril 2021.

BRASIL. Decreto-Lei no 2.848, de 7 de dezembro de 1940. Código Penal. Disponível em: http://www.planalto.gov.br/ccivil_03/decreto-lei/del2848compilado.htm. Acesso em: 23 jun. 2021.

BRASIL. Decreto-Lei $n^{\circ}$ 5.452, de 1 de maio de 1943. Aprova a Consolidação das Leis do Trabalho. Disponível em: http://www.planalto.gov.br/ccivil_03/decreto-lei/del5452.htm. Acesso em: 24 jun. 2021.

BRASIL. Lei $n^{\circ}$ 5.107, de 13 de setembro de 1966. Cria o Fundo de Garantia do Tempo de Serviço, e dá outras providências. Disponível em: http://www.planalto.gov.br/ccivil 03/leis/15107.htm. Acesso em: 03 abril 2021.

BRASIL. Lei $n^{\circ}$ 5.890, de 8 de junho de 1973. Altera a legislação de previdência social e dá outras previdências. Disponível em: http://www.planalto.gov.br/ccivil 03/leis/15890.htm. Acesso em: 03 abril 2021. 
BRASIL. Lei no 9.394, de 20 de dezembro de 1996. Estabelece as diretrizes e bases da educação nacional. Disponível em:

http://www.planalto.gov.br/ccivil 03/leis/19394.htm. Acesso em: 22 out. 2021.

BRASIL. Câmara dos deputados. Projeto de Lei no 3.179, de 08 de fevereiro de 2012. Acrescenta parágrafo ao art. 23 da Lei $n^{\circ}$ 9.394, de 1996, de diretrizes e bases da educação nacional, para dispor sobre a possibilidade de oferta domiciliar da educação básica. Disponível em: https://www.camara.leg.br/proposicoesWeb/fichadetramitacao?idProposicao $=534328$.

Acesso em: 23 jun. 2021.

BRASIL. Câmara dos deputados. Projeto de Lei no 4.657, de 16 de junho de 1994. Cria o ensino domiciliar de primeiro grau. Disponível em:

https://www.camara.leg.br/proposicoesWeb/fichadetramitacao?idProposicao=223311.

Acesso em: 22 jun. 2021.

IFTM. Resolução ad referendum $n^{\circ}$ 62, de 21 de maio de 2021. Disponível em: https://iftm.edu.br/visao/loader.php? src=025cb7eda86e $188139 f 056 \mathrm{c} 45 \mathrm{df} 2 \mathrm{e} 9 \mathrm{~d} 1$. Acesso em: 15 jun. 2021.

MARX, Karl. Teorias da mais-valia. Rio de Janeiro: Bertrand Brasil, 1987. Volume I.

PROST, Antoine; VINCENT, Gérard. (Org.) História da vida privada: Da Primeira Guerra a nossos dias. Volume 5. $7^{\text {a }}$ reimpressão. Companhia das Letras.

SOUZA, Kátia R. et al. Trabalho remoto, saúde docente e greve virtual em cenário de pandemia. Trabalho, Educação e Saúde, v. 19, 2021 . Disponível em:

https://doi.org/10.1590/1981-7746-soloo309. Acesso em: 22 jun. 2021. 